\title{
Peripheral Calcifying Odontogenic Cyst: A rare case report
}

\author{
Liana-Cristina-Melo-Carneiro Costa ${ }^{1}$, Joaquim-Barbosa-Matias Neto ${ }^{1}$, Eliene-Magda de-Assis ${ }^{1,3}$, Hayder-Egg \\ Gomes ${ }^{1}$, Tiago-Johnston Leitão ${ }^{4,5}$, Renzo-Rafael-Cevallos Vasconcelos ${ }^{6}$, Paulo-Eduardo-Alencar Souza ${ }^{1,2}$, \\ Martinho-Campolina-Rebello Horta ${ }^{1,2}$
}

\author{
${ }^{1}$ Graduate Program in Dentistry, School of Dentistry, Pontifical Catholic University of Minas Gerais (PUC Minas), Belo Horizonte, \\ MG, Brazil \\ ${ }^{2}$ Oral Pathology Section, School of Dentistry, Pontifical Catholic University of Minas Gerais (PUC Minas), Belo Horizonte, MG, \\ Brazil \\ ${ }^{3}$ Faculdade Pitágoras de Ipatinga, Ipatinga, MG, Brasil \\ ${ }^{4}$ Laboratório CIAP, Divinópolis, MG, Brasil \\ ${ }^{5}$ Federal University of Sao Joao del-Rei (UFSJ), Divinópolis, MG, Brasil \\ ${ }^{6}$ Private orthodontics practice, Divinópolis, MG, Brasil
}

Correspondence:

Departamento de Odontologia

Pontificia Universidade Católica de Minas Gerais Avenida Dom José Gaspar 500, Prédio 46, Sala 101 Belo Horizonte, Minas Gerais, Brasil, CEP: 30535-901 martinhohorta@pucminas.br
Costa LCMC, Neto JBM, de-Assis EM, Gomes HE, Leitão TJ, Vasconcelos RRC, Souza PEA, Horta MCR. Peripheral Calcifying Odontogenic Cyst: A rare case report. J Clin Exp Dent. 2018;10(11):e1140-4. http://www.medicinaoral.com/odo/volumenes/v10i11/jcedv10i11p1140.pdf

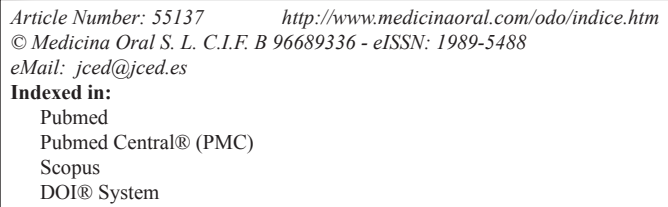

\begin{abstract}
The Calcifying Odontogenic Cyst (COC) is a simple cyst lined by ameloblastoma-like epithelium with ghost cells. The peripheral $\mathrm{COC}$ is a rare lesion and few reports have been published considering its clinical and histopathological features. This article aimed to report on a case of a peripheral COC, discussing its clinical, imaginological and histopathological features. A 9-year-old male patient presented a 10x5 mm painless nodule in the palatal mucosa of the left central incisor. Panoramic, occlusal and periapical radiographs did not show alterations. A computed tomography exam showed a slight soft tissue swelling located in the palatal mucosa of the left maxillary central incisor. An excisional biopsy was performed. The histopathological analysis showed a cystic lesion adhered to an oral mucosa fragment and lined by an ameloblastoma-like epithelium with ghost cells. The diagnosis of peripheral $\mathrm{COC}$ was established and the patient has been disease-free for 5 years. Although rare, peripheral COC is an important lesion that should be considered as a differential diagnosis of gingival hyperplastic lesions.
\end{abstract}

Key words: Calcifying odontogenic cyst, odontogenic tumors, peripheral calcifying odontogenic cyst.

\section{Introduction}

First described by Gorlin et al. in 1962 (1), the Calcifying Odontogenic Cyst (COC) is a simple cyst lined by ameloblastoma-like epithelium with ghost cells $(2,3)$. The 4th edition of the World Health Organization's Classification of Head and Neck Tumours, published in
2017, renamed and reclassified this lesion as an odontogenic cyst, since it had been categorized in 2005 as an odontogenic tumor (4).

$\mathrm{COC}$ is an uncommon lesion, representing $0.1 \%$ of all records and $1.3 \%$ of all odontogenic cysts in a recent multicentric study evaluating 198,350 histopathological 
records from oral and maxillofacial pathology services (3).

Although most of the $\mathrm{COC}$ are intraosseous, peripheral lesions can also occur. The peripheral COC show the same microscopic features of intraosseous $\mathrm{COC}$, but is located in the soft tissues of tooth-bearing areas (5). It is an even rarer lesion, corresponding to fewer than $3 \%$ of the COC (3).

This article aimed to report on a case of a peripheral COC diagnosed in a 9-year-old male, discussing its clinical, imaginological and histopathological features.

\section{Case Report}

A 9-year-old male patient accompanied by his mother sought dental assistance complaining of a palatal swelling. The lesion was painless and had initially been observed 5 months earlier. The medical history was noncontributory.

The intraoral physical examination revealed a $10 \times 5 \mathrm{~mm}$, ill-delimited, firm and sessile nodule, located in the palatal mucosa of the left central incisor (Fig. 1A,B). The overlying mucosa was intact and normal in color. Buccoversion of the adjacent teeth was observed, but no mobility or other periodontal alterations.

Panoramic, occlusal and periapical radiographs did not show alterations in the area adjacent to the lesion (Fig. 2A-C). A cone beam computed tomography (CBCT) exam also revealed no related bone alterations, but show a slight soft tissue swelling located in the palatal mucosa of the left maxillary central incisor (Fig. 2D).

The main diagnosis hypotheses included fibrous hyperplasia, peripheral ossifying fibroma, pyogenic granuloma and peripheral giant cell granuloma. An excisional biopsy was performed under local anesthesia. During the lesion's surgical removal, no superficial bone resorption was observed. Grossly, a cyst-like structure was observed adhered to the oral mucosa. The sample was sent to a Pathology Laboratory.

The histological examination revealed an oral mucosa fragment covered by a stratified squamous keratinized epithelium showing areas of hyperplasia (Fig. 3A). A cystic lesion was observed adhered to the deeper lamina propria (Fig. 3A-D). The cystic capsule, formed by dense fibrous connective tissue, was lined by an ameloblastoma-like epithelium (Fig. 3E). The basal layer cells of this lining epithelium were cubic or columnar, showing reversed polarity and hyperchromatic nuclei, disposed in palisade. The cells of the suprabasal layers were sometimes loosely arranged. Enlarged epithelial cells with eosinophilic cytoplasm and no nucleus (ghost cells) were sporadically found in the lining epithelium (Fig. 3E,F) and abundantly observed in the cyst lumen (Fig. 3C and G). Calcification of ghost cells was also observed (Fig. 3C-F). Juxtaepithelial dentinoid could be seen in the
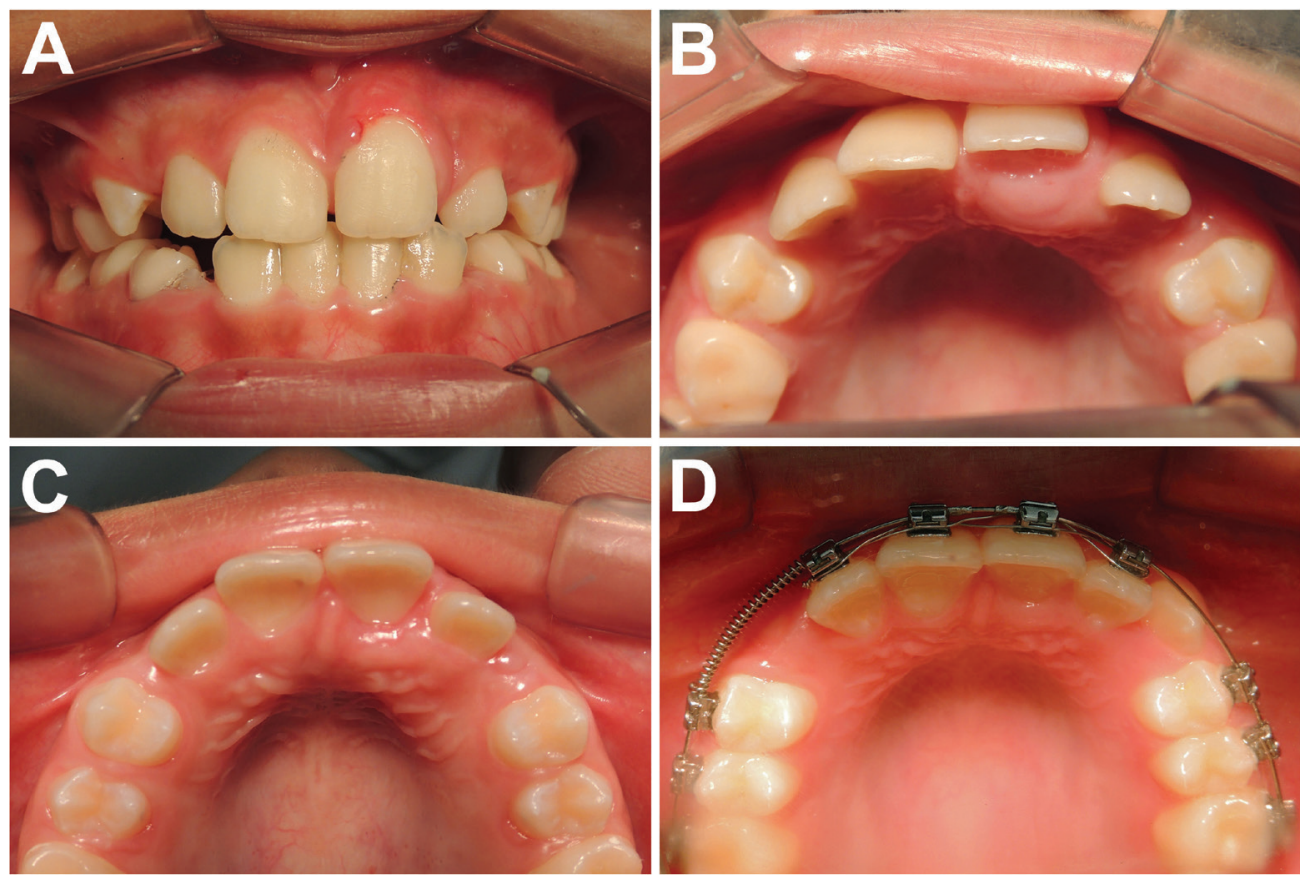

Fig. 1: A: Intraoral physical examination; B: Intraoral physical examination showing a 10x5 mm painless nodule in the palatal mucosa of the left central incisor; C: Follow-up visit two months after the excisional biopsy showing adequate healing; D: Follow-up visit one year after the surgical removal showing no recurrence. 

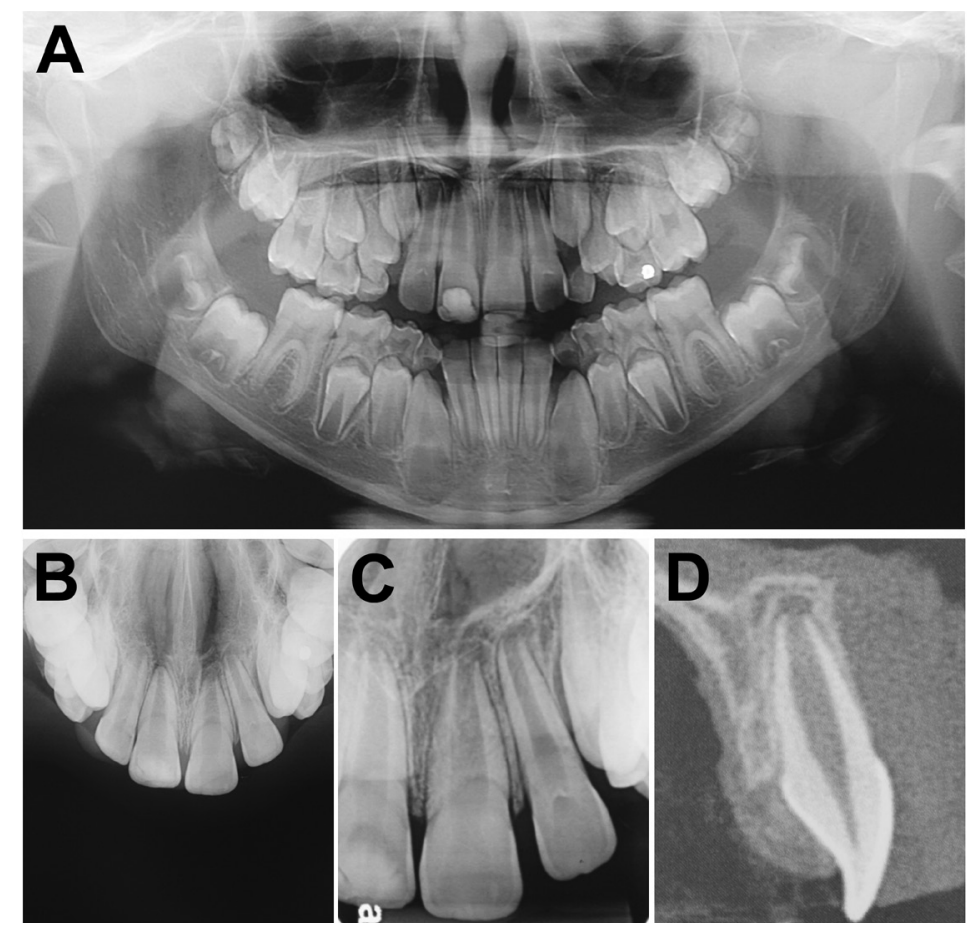

Fig. 2: A: Panoramic radiography with no related bone alterations; B: Occlusal radiography with no related bone alterations; C: Periapical radiography with no related bone alterations; D: Cone beam computed tomography (CBCT) exam showing no related bone alterations, but a slight soft tissue swelling in the palatal mucosa of the left maxillary central incisor.

cyst capsule (Fig. 3E). Moreover, soft and hard dental tissue resembling a developing odontoma were observed in the cyst wall (Fig. 3C,H).

The diagnosis of peripheral COC was established. In a follow-up visit two months after the excisional biopsy, the area was adequately healed (Fig. 1C). One year after the surgical removal, no recurrence was observed (Fig. 1D). The patient has been disease-free for 5 years. Informed consent has been obtained by the patient.

\section{Discussion}

The peripheral $\mathrm{COC}$ is a rare lesion and there are few studies in the literature concerning its clinical and histopathological features. In 1991, Buchner et al. (5) revised the 38 well-documented cases published in the English-language literature and reported additional 7 lesions, totalizing 45 cases. Afterward, Resende et al. (6) reviewed all the cases reported by Buchner et al. (5) and the succeeding reports from 1991 to 2010, finding 44 acceptable cases. Finally, Chrcanovic and Gomez (7) in a systematic review employing consistent eligibility criteria, found a total of 55 cases reported until 2016.

Peripheral COC can affect patients in a wide age range, with a mean of 41.8 years. There is a slight predilection for women, in which the lesion appears in a statistically higher age (49.1 years) when compared to men (33.3 years) (7). The case reported occurred in a 9-year-old male patient, much younger than this average age. In fact, only one of the 45 peripheral COC reported by Buchner $e t$ $a l$. (5) affected patients between 0 and 9 years old.

Most of the reported peripheral COC developed as painless, well-delimited and smooth-surface nodules on the gingiva or alveolar mucosa $(5,6)$. The lesion size varies from 0.5 to $3.0 \mathrm{~cm} \mathrm{(7).} \mathrm{The} \mathrm{majority} \mathrm{of} \mathrm{the} \mathrm{cases}$ affects the mandible and the incisor-canine area is the most common location (7). The reported case presented almost all these clinical features. As described in the present case, the most common clinical differential diagnosis are common gingival hyperplastic lesions $(5,6)$.

The histopathological analysis of the reported case disclosed typical findings of COC such as the fibrous connective capsule lined by an ameloblastoma-like epithelium and the presence of ghost cells, as well as areas of dentinoid formation in the capsule (8-10). Moreover, soft and hard dental tissue resembling a developing odontoma were observed in the cyst wall, similar to one of the cases reported by Buchner et al. (5).

Conservative surgical excision is the standard treatment for peripheral $\mathrm{COC}$ and recurrences are rare (5-7). This surgical approach was effective in the case reported, with no signs of recurrence after a 5-year follow-up.

Although rare, peripheral COC is an important lesion that should be considered as a differential diagnosis of gingival hyperplastic lesions. 

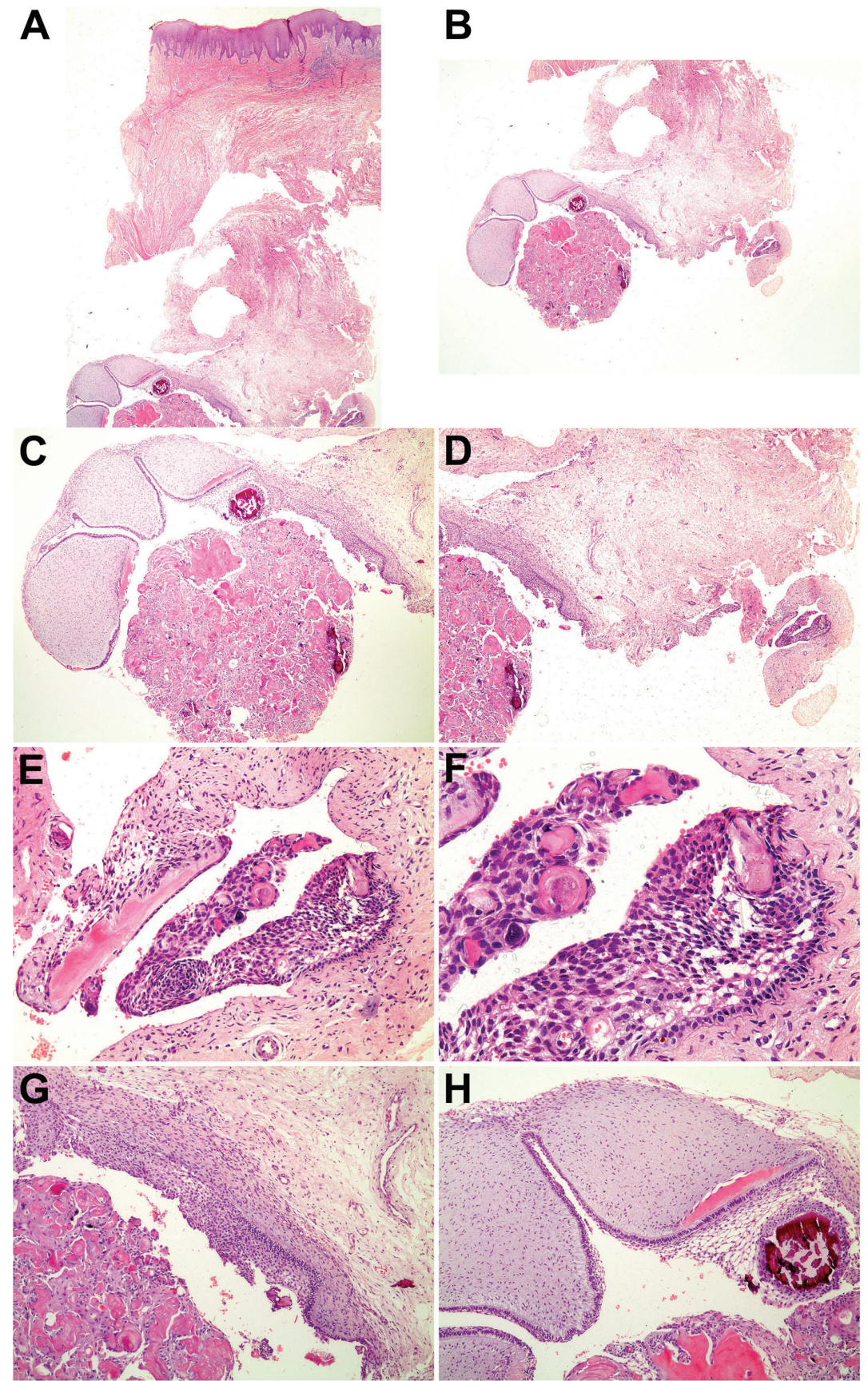

Fig. 3: A, B, C, D: Microscopic examination showing an oral mucosa fragment with a cystic lesion adhered to the deeper lamina propria (A: HE x20; B: HE x20; C: HE x40; D: HE x40); $\mathrm{E}$ and F: The cystic capsule was lined by an ameloblastoma-like epithelium with ghost cells showing occasional calcification (E: HE x200; F: HE x400); G: Ghost cells were abundantly observed in the cyst lumen (HE x100); $\mathrm{H}$ : Soft and hard dental tissue resembling a developing odontoma in the cyst wall (HE x100).

\section{References}

1. Gorlin RJ, Pindborg JJ, Clausen FP, Vickers RA. The calcifying odontogenic cyst--a possible analogue of the cutaneous calcifying epithelioma of Malherbe. An analysis of fifteen cases. Oral Surg Oral Med Oral Pathol. 1962;15:1235-43.

2. Soluk-Tekkeşin M, Wright JM. The World Health Organization Classification of Odontogenic Lesions: A Summary of the Changes of the 2017 (4th) Edition. Turk Patoloji Derg. 2018;34.
3. de Arruda JAA, Schuch LF, Abreu LG, Silva LVO, Monteiro JLG, Pinho RF, et al. A multicentre study of 268 cases of calcifying odontogenic cysts and a literature review. Oral Dis. 2018.

4. Wright JM, Vered M. Update from the 4th Edition of the World Health Organization Classification of Head and Neck Tumours: Odontogenic and Maxillofacial Bone Tumors. Head Neck Pathol. 2017;11:68-77.

5. Buchner A, Merrell PW, Hansen LS, Leider AS. Peripheral (extraos- 
seous) calcifying odontogenic cyst. A review of forty-five cases. Oral Surg Oral Med Oral Pathol. 1991;72:65-70.

6. Resende RG, Brito JA, Souza LN, Gomez RS, Mesquita RA. Peripheral calcifying odontogenic cyst: a case report and review of the literature. Head Neck Pathol. 2011;5:76-80.

7. Chrcanovic BR, Gomez RS. Peripheral calcifying cystic odontogenic tumour and peripheral dentinogenic ghost cell tumour: an updated systematic review of 117 cases reported in the literature. Acta Odontol Scand. 2016;74:591-7.

8. Hong SP, Ellis GL, Hartman KS. Calcifying odontogenic cyst. A review of ninety-two cases with reevaluation of their nature as cysts or neoplasms, the nature of ghost cells, and subclassification. Oral Surg Oral Med Oral Pathol. 1991;72:56-64.

9. Yoshida M, Kumamoto H, Ooya K, Mayanagi H. Histopathological and immunohistochemical analysis of calcifying odontogenic cysts. J Oral Pathol Med. 2001;30:582-8.

10. Fregnani ER, Pires FR, Quezada RD, Shih IeM, Vargas PA, de Almeida OP. Calcifying odontogenic cyst: clinicopathological features and immunohistochemical profile of 10 cases. J Oral Pathol Med. 2003;32:163-70.

\section{Acknowledgments}

This study was supported by grants from Fundação de Amparo à Pesquisa do Estado de Minas Gerais (FAPEMIG CDS-PPM-00653-16), The authors are grateful to Coordenação de Aperfeiçoamento de Pessoal de Nível Superior (CAPES) and Conselho Nacional de Desenvolvimento Científico e Tecnológico (CNPq). MCRH is a research fellow of FAPEMIG (CDS-PPM-00653-16). EMA has a CAPES fellowship. HEG has a PUC Minas fellowship.

\section{Conflicts of Interest}

None. 